\title{
Defining and Monitoring Power Measurement in Elite Swimmers
}

\author{
Emma Swanwick* \\ School of Health Sciences, University of Salford, Frederick Road, Salford M6 6PU, UK \\ *Corresponding author: ek.swanwick@gmail.com
}

\begin{abstract}
The measurement of power in swimming has previously been carried out using a number of different methods. Each method appears to produce differing wattages, the majority of which are far below those seen in athletes of a similar level in other sports. The aim of this paper was to define what is being measured, what it relates to, and to give appropriate titles to the "types of power" recorded.
\end{abstract}

Keywords: power, swimming kinetic, thrust

Cite This Article: Emma Swanwick, and Martyn Matthews, "Defining and Monitoring Power Measurement in Elite Swimmers." American Journal of Sports Science and Medicine, vol. 5, no. 3 (2017): 57-63. doi: 10.12691/ajssm-5-3-4.

\section{Introduction}

Power in sports can be derived in 3 different terms: (1) - power that is generated within the body by conversion of $\mathrm{ATP}$ to $\mathrm{ADP}+\mathrm{P}$ and is a function of the amount of muscle mass engaged and the speed at which it is delivered; (2) power output that can be delivered as a force and (3) - the power required to maintain the kinetic energy of a body or object [1].

Identification of power has been difficult to quantify in swimming let alone in its many applicable forms. Schultz and Webb [2] suggested that, from fish models, net metabolic rates are consistent with drag. In these models the tail is seen as a discrete propeller and body drag is treated as a separate entity. Such a model works on the basis that undulation movements (not unlike in human swimming) are energetically expensive. Additionally, they consider that due to most drag calculations being based on rigid body models (a body towed through water) $[3,4]$, that such models only cause confusion as drag and thrust cannot be separated, so have no meaning for selfpropelling bodies [2]. Other models of power calculation in hydrodynamic conditions have focused on thrust and drag, however at constant velocity both thrust and Froude efficiency can be zero [3]. The issue of drag measurement is the decomposition of momentum changes and that the measure of drag is potentially the measurement of shear forces [6]. We should view this as simply power loss [2]. By doing this, changes in drag are more reliable and easily understood.

In such a model, it is relatively easy to calculate thrust and drag. In steady speeds however, thrust can be zero, as can Froude efficiency (Froude efficiency is $(\mathrm{v} / 2 \pi \mathrm{SF} 1)(2 / \pi)$ where $\mathrm{v}=$ velocity, SF is stroke frequency, 1 is the assumed arm length of $0.52 \mathrm{~m}$ [3]. In this situationIn a practical sense, however, there are really only 2 features that are important in swimming; speed and power. Such an approach only needs a few parameters, fluid density, swimming speed, internal energy, rate of work, volume of working muscle.

As swimming speed is directly related to the effective mechanical power output generated by the athlete $[7,8]$, its measurement holds a great deal of relevance to the development of swimming performance. Sharp et al. [9] related power measured on a bio-kinetic swim bench to that of 25yds maximal swim time and reported good reliability and Hawley et al. [10] demonstrated that muscle power measured through a bicycle and arm Wingate tests also showed good predictability of freestyle performance in events from $50 \mathrm{~m}$ to $400 \mathrm{~m}$. Hollander et al [12] described a mechanism for measuring force resistance and fitting this with measurements of active drag from which propulsive forces could be derived. Toussaint and other authors have then used this to identify power transfer in swimmers and their overall efficiency $[4,6,8,12]$

When a review of power of athletes of similar levels across sports is carried out (see Table 1), it quickly becomes evident that for the most part values of power (watts or watts $/ \mathrm{kg}$ ) are similar at a range of relative intensities, with the exception of swimming. Swimming power, measured in the water, has been significantly lower than those of a range of other sports. Is this because the swimmers are producing less power or is it that the "type" of power measure reported is different? Defining if the power is internal, external, kinetic or thrust are important for the development of understanding of the application of power to the practical and training situation.

The many terms that are used in describing power can lead to lay people sometimes being confused by the measurement of power in the pool environment. This may have led to why it is not often monitored in swimming. Zamparo et al [5] described that the total work was made up of the work needed to accelerate and decelerate limbs with respect to the centre of mass (internal work or power 
input) and the work needed to overcome external forces. The latter was also broken down into that force which overcomes drag and contributes to thrust and the kinetic work that does not add to thrust but does add energy to the water. The terms used in that study would appear to be more appropriate to use and were adopted for this study.

The contribution of lactate to the overall metabolic power during cycling has been considered [13]. This allowed better calculation of power (watts) during anaerobic metabolism. Other authors have also investigated the energetics of power output as a function of velocity in swimming but these were at a submaximal speed [14]. The amount of metabolic energy spent during what was described as supra maximal swims ( $45.7 \mathrm{~m} 91.4 \mathrm{~m} \& 182.9 \mathrm{~m})$ where swimmers were unable to use competition turns or push off the wall has been described also [13]. The calculations were previously explained by Di Pramparo [15] and Toussaint \& Hollander [16]. The calculated energy (Kilojoules) as a function of the energy equivalent of $\mathrm{O}_{2}$, the amount of energy derived from anaerobic stores (the energy equivalent of blood lactate accumulation), body mass, and time. Total power outputs were described to average $2720 \mathrm{w}$ for 100 freestyle swims and 1940 watts for $200 \mathrm{~m}$ freestyle swims. We are assuming that these values relate to what Zamparo et al [5] described as internal power, that is, the power that is generated within the body before it is applied. As such, these values are higher than those suggested by a standard calculation of watts (where watts $=1000 \mathrm{x}$ $\mathrm{E}(\mathrm{kj}) /$ time $)$, and appear high in relation to time lines when compared to swimming and other sports (Table 1).

We wished to look at two major elements of the wattage output of swimmers in submaximal and maximal swims in relation to the application in competitive distances. Firstly, could the internal power generated be more easily described in terms of Mass, time and lactate, and secondly, can the values described for swimming be more clearly related to those observed in other sports. Through this we hoped to create definitions of different aspects of power and to identify them in a swimming model that can be more readily accessed and understood.

Table 1. Summary of power test results in swimming \& other sports.

\begin{tabular}{|c|c|c|c|c|c|c|c|c|}
\hline Author & year & type & sport & N -1 & $\begin{array}{l}\text { Age } \\
\text { (Yrs) }\end{array}$ & time line & Power (W) & $\begin{array}{l}\mathrm{W} / \mathrm{kg} \\
\text { relative }\end{array}$ \\
\hline $\begin{array}{l}\text { Sharp, RL; Troup, J.P; } \\
\text { Costill, D.L }\end{array}$ & 1982 & $\begin{array}{l}\text { Biokinetic } \\
\text { swim bench }\end{array}$ & swimmers & $\begin{array}{l}\mathrm{N}=40 \\
(18 \mathrm{M} \\
22 \mathrm{FM})\end{array}$ & $\begin{array}{l}15.23 \pm \\
0.27\end{array}$ & $\begin{array}{c}10 \text { double } \\
\text { arm pulls } \\
(15-18 \mathrm{sec})\end{array}$ & $\begin{array}{c}\mathrm{M}=286 \pm 14.2 \mathrm{~W} \\
\mathrm{FM}=164.5 \pm 11.9 \mathrm{~W} \\
\text { Mean } 219.25 \pm 15.9 \mathrm{~W}\end{array}$ & \\
\hline $\begin{array}{l}\text { Toussaint, H.M; } \\
\text { Vervoorn, K }\end{array}$ & 1990 & MAD & swimmers & 11 & & $23 \mathrm{~m}$ & $160-170 w$ & \\
\hline $\begin{array}{c}\text { Toussaint, H.M; } \\
\text { Knops, W; De Groot, } \\
\text { G; Hollander, A.P; }\end{array}$ & 1990 & MAD & Swimmers & 10 & & $\begin{array}{c}\text { velocity } \\
0.95- \\
1.6 \mathrm{~m} . \mathrm{s}-1\end{array}$ & $26-108 \mathrm{~W}$ & \\
\hline $\begin{array}{c}\text { Denadai, B.S; } \\
\text { Figuera, T.R; } \\
\text { Goncalves, M; }\end{array}$ & 2004 & cycling & cyclists & 9 & & MLSS & $282.1 \pm 23.8$ & $4.1 \pm 0.7$ \\
\hline $\begin{array}{l}\text { koutedakis,Y; Sharp, } \\
\text { N.C.C; }\end{array}$ & 1986 & Wingate & elite rowers & 8 & $\begin{array}{l}17.6 \\
\pm 0.7\end{array}$ & $30 \mathrm{sec}$ & $\begin{array}{l}\text { peak } \mathrm{Pwr}=979.50 \pm 73.6 \\
\text { Mean } \mathrm{Pwr}=849.37 \pm 67.7\end{array}$ & $\begin{array}{l}11.77 \text { peak } \\
\text { Pwr }=0.45\end{array}$ \\
\hline $\begin{array}{l}\text { koutedakis,Y; Sharp, } \\
\text { N.C.C; } \\
\end{array}$ & 1986 & Wingate & club rowers & 16 & $\begin{array}{c}17.3 \pm \\
0.6\end{array}$ & $30 \mathrm{sec}$ & $\begin{aligned} \text { peak Pwr } & =716.37 \pm 80.3 \\
\text { Mean Pwr } & =610.18 \pm 69.3\end{aligned}$ & $\begin{array}{c}9.5 \text { peak } \\
\text { Pwr }=0.78\end{array}$ \\
\hline Beneke, R; & 1995 & MLSS & club rowers & 9 & $20 \pm 1.6$ & $30 \mathrm{mins}$ & $\begin{array}{l}\text { AT4mmol/1 pwr }=287.1 \pm 25.1 \\
\text { MLSS } 3 \mathrm{mmo} / 1255.1 \pm 17.5 \mathrm{~W}\end{array}$ & \\
\hline $\begin{array}{c}\text { Grossi,T; De } \\
\text { Lucas,R.D; Mendes } \\
\text { de Souza, } \sim \mathrm{K} ; \\
\text { Guilherme, L; } \\
\text { Guglielmo, A: }\end{array}$ & 2012 & $\begin{array}{l}\text { Intermitant } \\
\text { MLSS }\end{array}$ & $\begin{array}{l}\text { trained } \\
\text { cyclists }\end{array}$ & 14 & & $\begin{array}{l}5 \min \text { ex: } 1 \\
\text { min rest to } \\
\text { exhaustion }\end{array}$ & $\begin{array}{l}\text { Intermittent }=268 \pm 29 \mathrm{~W} \\
\quad \text { MLSS }=251 \pm 29 \mathrm{~W}\end{array}$ & \\
\hline $\begin{array}{c}\text { Basset, J.R; Kyle, } \\
\text { C.R; Passfield, L; } \\
\text { Broker, J.P; Burke, } \\
\text { E.R; }\end{array}$ & 1999 & $\begin{array}{l}1 \text { hour } \\
\text { Time Trial }\end{array}$ & $\begin{array}{l}\text { elite } \\
\text { cyclists }\end{array}$ & $\begin{array}{l}\text { review of } \\
1 \text { hour } \\
\text { record }\end{array}$ & & 1 hour & $440 \mathrm{~W}$ & \\
\hline Mujika,I; Padilla,S; & 2001 & stage racing & $\begin{array}{l}\text { Prof } \\
\text { cyclists }\end{array}$ & $\begin{array}{l}\text { review of } \\
\text { TDF data }\end{array}$ & $\begin{array}{c}18-33 \\
\text { yrs }\end{array}$ & 1-6 hours & $\begin{array}{c}\mathrm{LT}=370-390 \mathrm{~W} \\
\mathrm{OBLA}=400-420 \mathrm{~W}\end{array}$ & \\
\hline $\begin{array}{l}\text { Scharbolt, E.J; } \\
\text { Hawley,J.A; } \\
\text { Hopkins,W.G; } \\
\text { Blum,H; }\end{array}$ & 1999 & $\begin{array}{l}\text { concept II } \\
\text { erg }\end{array}$ & elite rowers & 8 & & 7 mins & $313 \pm 38 \mathrm{~W}$ & \\
\hline Hagerman F.C; & 1984 & racing & elite rowers & $\begin{array}{l}\text { Pooled } \\
\text { Data }\end{array}$ & & $\begin{array}{c}\text { Male }=6 \\
\text { mins } \\
\text { Female }=3 \\
\text { mins }\end{array}$ & $\begin{array}{c}\text { Male }=390 \pm 13.6 \mathrm{~W} \\
\text { Female }=300 \pm 18.4 \mathrm{~W}\end{array}$ & \\
\hline \multirow[t]{2}{*}{$\begin{array}{l}\text { Billat, V; faina, M; } \\
\text { Sardella,F; Marini, C; } \\
\text { Lupo, S; }\end{array}$} & 1996 & $\mathrm{VO}_{2} \mathrm{Max}$ & $\begin{array}{l}\text { National } \\
\text { Cyclists }\end{array}$ & 9 & & $222 \pm 91 \mathrm{sec}$ & $419 \pm 49 \mathrm{~W}$ & \\
\hline & & $\mathrm{VO}_{2} \mathrm{Max}$ & $\begin{array}{l}\text { National } \\
\text { Kayakers }\end{array}$ & 9 & & $\begin{array}{c}376 \pm 134 \\
\text { sec }\end{array}$ & $239 \pm 56 \mathrm{~W}$ & \\
\hline $\begin{array}{l}\text { van Ingen Schenau } \\
\text { GJ ,Ê de Koning JJ ,Ê } \\
\text { de Groot G Ê }\end{array}$ & 1994 & racing & $\begin{array}{l}\text { Speed } \\
\text { skaters }\end{array}$ & $\begin{array}{l}\text { Review } \\
\text { of } \\
\text { Olympic } \\
500 \mathrm{~m} \\
\end{array}$ & $\begin{array}{c}17-23 \\
\text { yrs }\end{array}$ & $80-100 \mathrm{sec}$ & & $10 \mathrm{~W} / \mathrm{kg}$ \\
\hline
\end{tabular}




\section{Calculations}

In swimming, unlike other sports, the body is supported by the water to a degree. This is related to the density of the body (dependent particularly but not solely on the bone mass, muscle mass and fat mass) and the density of the water (reliant on the water temperature). The mass of the body that is not supported by the water (that which is below the waterline) can be calculated through the calculation of body density in the pool water [17]. This was assumed as the Active mass of the body of the swimmer, that is the mass upon which force has to be applied and the body upon which drag and resistance is applied. Velocity is the function of speed (distance /time) and the energy, rather than converting to kilojoules, was left as the relative post swim blood lactate. This therefore relates both to the calculation of previous authors $[13,18]$ who defined power input is a function of energy, time and body mass,

Work Internal $\left(\mathbf{W}_{\text {int }}\right)$ Power output = $\left((\text { Lactate })^{*}(\text { vel*vel })^{*}\right.$ active body mass $(\mathrm{kg})$ lactate is the measurement of energy, mean velocity during the swim represents the time element, whereas velocity ${ }^{2}$ is proportional to the resistance [19]. This means that in this calculation we are taking account of the overall internal energy (expressed as power in watts) required to overcome resistance at each swimming speed for the active mass of the body to create and maintain momentum in the water. A proportion of this will be lost as heat, and through internal and external efficiency of the joints and muscle movement as well as drag.

$$
\text { Work Kinetic }\left(\mathbf{W}_{\mathbf{k}}\right)=1 / 2 M * \mathrm{~V}^{2}
$$

Where $\mathrm{M}$ is the mass of the body in $\mathrm{kg}$ multiplied by the resistance $\left(\mathrm{V}^{2}\right)$. Kinetic energy is then the work needed to accelerate a body of a given mass from rest to its stated velocity (v) having gained this energy during its acceleration, the body maintains this kinetic energy unless its speed changes (Wikipedia).

\section{Work Total $\left(\mathbf{W}_{\text {tot }}\right)$ Power Input $=\left(\mathrm{W}_{\mathrm{int}}+\mathrm{W}_{\mathrm{k}}\right)$.}

This is the total amount of chemical energy to create and maintain the momentum of the body, including acceleration, deceleration (during cyclic movements).

\section{Work to overcome drag or Thrust}

$$
=\mathrm{W}_{\text {int }} /\left(\text { vel }^{\text {to the powervel }}\right) \text {. }
$$

Thrust is the force that can be applied at a given moment, and is made up of work that is generated to overcome drag to be useful in propulsion [3]. Thrust is a sum of all the energy required in the body to continue acceleration. This is proportional to the internal work divided by form drag $D_{\mathrm{f}}$. $\mathrm{D}_{\mathrm{f}}$ is equal to velocity to the power of the velocity [20,21].

\section{Power as a function of body mass}

$$
=\mathrm{W}_{\mathrm{int}} / \text { body } \operatorname{mass}(\mathrm{kg}) \text {. }
$$

Thrust as a function of the mass of the body. This is used in many sports as a power to weight ratio.

Thrust in kg transferred to the water.

$$
=\left((\text { Thrust / 9.81 })-\left(\mathrm{W}_{\mathrm{k}} / 9.81\right)\right) / \text { vel. }
$$

In swimming only a certain amount of force can be applied to water until the water being acted upon will begin to move. As such any force that is generated must be applied through swimming skill, while causing the minimum water slippage. This measurement therefore is not only a measure of power generated but of the skill to apply this force. Both thrust and $\mathrm{W}_{\mathrm{k}}$ have been described above in watts. To convert this to kilograms load, we used the accepted conversion of 1.0 watt $=1$ newton $/ \mathrm{sec}^{2}$ and that 1 kilogram $=9.81$ newtons. The value then is expressed as $\mathrm{kg} / \mathrm{sec}^{2}$.

\section{Methods}

Subjects: 27 subjects took part in this exercise. Of which 13 were females and 14 were males. Basic characteristics are shown in Table 2.

Table 2. Summary of subjects who participated in the study

\begin{tabular}{|c|c|c|c|c|c|c|}
\hline & \multicolumn{2}{|c|}{ Age } & \multicolumn{2}{c|}{ Mass } & \multicolumn{2}{c|}{ Lean Body Mass } \\
\hline & Female & Male & Female & Male & Female & Male \\
\hline Number & 13 & 14 & & & & \\
\hline Mean & 19.00 & 18.93 & 63.64 & 78.08 & 53.49 & 70.57 \\
\hline St Dev & 2.86 & 2.13 & 4.26 & 7.67 & 3.15 & 7.74 \\
\hline
\end{tabular}

All swimmers involved were competing either at Commonwealth, World or Olympic level. They were involved in regular training between 8-10 pool sessions per week, between 16 and 20 hours pool time as well as up to 6 hours land work consisting of resistance training circuits, strength training and flexibility work. All subjects were informed of the protocols, which they had all undertook previously as part of their on going training monitoring. Prior to their volunteering, each subject was fully informed of the study and signed an informed consent form approved by Christchurch College of Education Ethics Committee.

Prior to testing, each subject was assessed for weight, skinfolds and lean body mass (LBM) calculated. Subjects report to the pool 45 minutes prior to the test starting time. They were allowed to do their normal pre swimming land based warm up before completing a standardized warm up lasting 20 minutes.

The subjects performed a graded sub-maximal swimming test of $7 \times 200$ meter freestyle swims as a basis for the stepped assessment to a maximal effort final swim. This testing was conducted in accordance with the protocols of the Australian National Swimming Team [22].

Lactate profiling. 7 × $200 \mathrm{~m}$ step test was conducted on a 6:30 min cycle. Dietary intake, 24-hour prior training load, and pre-test warm-up were all standardized for each test. The seven swims were performed at an even pace, controlled by the swimmer. Each swimmer was provided with individual target times based upon the personal best performance on freestyle over $200 \mathrm{~m}$. The range of target times was approximately 30 seconds and progressed from slowest to fastest in consistent increments $(19,20)$. This progression equates to an approximate rise in intensity from $70 \%$ of maximal (first swim) to $100 \%$ of maximal effort (seventh swim). 
Each $200 \mathrm{~m}$ swim began with a push start while partially submerged in the water. Mean swimming velocity over the $200 \mathrm{~m}$ was recorded for each effort as well as the $100 \mathrm{~m}$ split times using a manual stopwatch. Stroke count was recorded for each 50-meter lap to allow the calculation of the stroke characteristics (distance per stroke and the stroke rate). Heart rate was monitored immediately on completion of each swim with a Polar heart rate monitor (Polar Electro OY, Kempele, Finland). Capillary blood $(25 \mu \mathrm{l})$ was collected from finger-tip or ear lobe puncture one minute after the completion of each swim. Lactate concentration was analyzed by a Lactate Pro Lactate meter (Axon Labs., Austria). All tests were completed at the same time of day.

\section{Results}

After the completion of the $7 \times 200 \mathrm{~m}$ progressive swim test, the results and calculated power measurements were computed. These are shown in Table 3 for males and Table 4 for females.

Table 3. The mean power values at specific lactates and their corresponding times for the male swimmers $(\mathrm{n}=14)$

\begin{tabular}{|c|c|c|c|c|c|c|c|c|c|}
\hline \multicolumn{10}{|c|}{ Male } \\
\hline & lactate & time & $\mathrm{W}_{\text {tot }}$ & $\mathrm{W}_{\text {int }}$ & Thrust $\left(\mathrm{W}_{\mathrm{d}}\right)$ & $\mathrm{W}_{\mathrm{k}}$ & watt $/ \mathrm{kg}$ & watt $/ \mathrm{kg}$ & $\mathrm{kg}$ transfer \\
\hline \multirow{3}{*}{1.0} & mean & $02: 16.2$ & 180.23 & 88.54 & 51.67 & 91.69 & 1.14 & 0.66 & 1.65 \\
\hline & St Dev & $00: 06.2$ & 18.15 & 9.95 & 5.62 & 11.76 & 0.10 & 0.02 & 0.65 \\
\hline & confidence & $00: 00.2$ & 0.63 & 0.35 & 0.20 & 0.41 & 0.00 & 0.00 & 0.02 \\
\hline \multirow{3}{*}{3.0} & mean & $02: 12.8$ & 381.59 & 281.56 & 154.91 & 100.03 & 3.61 & 1.98 & 6.89 \\
\hline & St Dev & $00: 05.7$ & 37.38 & 31.10 & 17.21 & 12.38 & 0.29 & 0.05 & 1.57 \\
\hline & confidence & $00: 00.2$ & 1.30 & 1.08 & 0.60 & 0.43 & 0.01 & 0.00 & 0.05 \\
\hline \multirow{3}{*}{4.0} & mean & $02: 11.0$ & 491.48 & 386.84 & 206.22 & 104.63 & 4.96 & 2.64 & 10.13 \\
\hline & St Dev & $00: 05.5$ & 49.21 & 42.99 & 23.15 & 12.99 & 0.40 & 0.07 & 2.05 \\
\hline & confidence & $00: 00.2$ & 1.72 & 1.50 & 0.81 & 0.45 & 0.01 & 0.00 & 0.07 \\
\hline \multirow{3}{*}{5.0} & mean & $02: 09.3$ & 608.15 & 498.60 & 257.11 & 109.55 & 6.40 & 3.29 & 13.24 \\
\hline & St Dev & $00: 05.4$ & 63.04 & 56.38 & 29.17 & 13.88 & 0.53 & 0.09 & 2.52 \\
\hline & confidence & $00: 00.2$ & 2.20 & 1.96 & 1.02 & 0.48 & 0.02 & 0.00 & 0.09 \\
\hline \multirow{3}{*}{8.0} & mean & $02: 04.1$ & 1004.71 & 878.13 & 405.52 & 126.58 & 11.27 & 5.19 & 21.63 \\
\hline & St Dev & $00: 05.6$ & 123.84 & 112.50 & 47.69 & 19.09 & 1.12 & 0.18 & 4.00 \\
\hline & confidence & $00: 00.2$ & 4.32 & 3.92 & 1.66 & 0.67 & 0.04 & 0.01 & 0.14 \\
\hline \multirow{3}{*}{10.0} & mean & $02: 00.7$ & 1315.03 & 1174.75 & 498.85 & 140.28 & 15.07 & 6.38 & 26.35 \\
\hline & St Dev & $00: 06.0$ & 190.43 & 172.50 & 60.90 & 25.56 & 1.79 & 0.28 & 5.14 \\
\hline & confidence & $00: 00.2$ & 6.64 & 6.01 & 2.12 & 0.89 & 0.06 & 0.01 & 0.18 \\
\hline \multirow{3}{*}{ Max } & mean & $01: 56.4$ & 1815.32 & 1658.67 & 641.59 & 156.65 & 21.14 & 8.17 & 33.25 \\
\hline & St Dev & $00: 02.9$ & 394.85 & 397.81 & 165.36 & 11.37 & 4.05 & 1.73 & 10.24 \\
\hline & confidence & 00:00.1 & 13.76 & 13.86 & 5.76 & 0.40 & 0.14 & 0.06 & 0.36 \\
\hline \multirow{3}{*}{ MVO2 } & mean & $01: 57.9$ & 1079.09 & 951.45 & 481.29 & 130.04 & 12.74 & 5.42 & 22.06 \\
\hline & St Dev & $00: 02.4$ & 181.35 & 185.99 & 109.46 & 14.86 & 2.13 & 0.95 & 6.23 \\
\hline & confidence & 00:00.1 & 6.32 & 6.48 & 3.82 & 0.52 & 0.07 & 0.03 & 0.22 \\
\hline
\end{tabular}

Table 4. The mean power values at specific lactates values with their corresponding times for the female swimmers $(\mathrm{n}=13)$

\begin{tabular}{|c|c|c|c|c|c|c|c|c|c|}
\hline \multicolumn{10}{|c|}{ Female } \\
\hline & lactate & time & $\mathrm{W}_{\text {tot }}$ & $\mathrm{W}_{\mathrm{int}}$ & Thrust $\left(\mathrm{W}_{\mathrm{d}}\right)$ & $W_{k}$ & watt $/ \mathrm{kg}$ & watt $/ \mathrm{kg}$ & $\mathrm{kg}$ transfer \\
\hline \multirow{3}{*}{1.0} & mean & $02: 24.1$ & 139.43 & 60.86 & 39.03 & 78.57 & 0.96 & 0.62 & 0.59 \\
\hline & St Dev & $00: 09.2$ & 19.50 & 7.12 & 2.17 & 12.90 & 0.12 & 0.02 & 0.22 \\
\hline & confidence & $00: 00.3$ & 0.68 & 0.25 & 0.08 & 0.45 & 0.00 & 0.00 & 0.01 \\
\hline \multirow{3}{*}{3.0} & mean & $02: 20.2$ & 279.46 & 193.72 & 117.74 & 85.73 & 3.06 & 1.86 & 4.95 \\
\hline & St Dev & $00: 07.5$ & 30.93 & 19.94 & 6.49 & 12.13 & 0.34 & 0.06 & 0.73 \\
\hline & confidence & 00:00.3 & 1.08 & 0.69 & 0.23 & 0.42 & 0.01 & 0.00 & 0.03 \\
\hline \multirow{3}{*}{4.0} & mean & $02: 18.3$ & 355.99 & 266.30 & 157.25 & 89.69 & 4.20 & 2.48 & 7.57 \\
\hline & St Dev & 00:06.6 & 35.92 & 25.67 & 8.67 & 11.67 & 0.43 & 0.07 & 0.91 \\
\hline & confidence & 00:00.2 & 1.25 & 0.89 & 0.30 & 0.41 & 0.01 & 0.00 & 0.03 \\
\hline \multirow{3}{*}{5.0} & mean & $02: 16.4$ & 437.36 & 343.43 & 196.71 & 93.93 & 5.42 & 3.10 & 10.10 \\
\hline & St Dev & 00:05.8 & 40.56 & 31.08 & 10.88 & 11.17 & 0.51 & 0.09 & 1.07 \\
\hline & confidence & $00: 00.2$ & 1.41 & 1.08 & 0.38 & 0.39 & 0.02 & 0.00 & 0.04 \\
\hline \multirow{3}{*}{8.0} & mean & $02: 10.6$ & 714.76 & 606.10 & 313.50 & 108.66 & 9.56 & 4.94 & 17.00 \\
\hline & St Dev & $00: 03.9$ & 56.65 & 48.90 & 17.31 & 10.06 & 0.71 & 0.14 & 1.45 \\
\hline & confidence & 00:00.1 & 1.97 & 1.70 & 0.60 & 0.35 & 0.02 & 0.00 & 0.05 \\
\hline \multirow{3}{*}{10.0} & mean & 02:06.8 & 932.79 & 812.23 & 388.36 & 120.57 & 12.81 & 6.12 & 20.93 \\
\hline & St Dev & 00:03.6 & 78.17 & 69.39 & 21.06 & 11.09 & 0.90 & 0.18 & 1.72 \\
\hline & confidence & 00:00.1 & 2.72 & 2.42 & 0.73 & 0.39 & 0.03 & 0.01 & 0.06 \\
\hline \multirow{3}{*}{ Max } & mean & 02:06.5 & 931.83 & 810.02 & 382.05 & 121.81 & 12.88 & 6.06 & 20.36 \\
\hline & St Dev & 00:04.2 & 150.38 & 140.04 & 44.67 & 12.00 & 2.57 & 0.87 & 2.33 \\
\hline & confidence & 00:00.1 & 5.24 & 4.88 & 1.56 & 0.42 & 0.09 & 0.03 & 0.08 \\
\hline \multirow{3}{*}{ MVO2 } & mean & 02:05.9 & 712.46 & 604.85 & 382.12 & 108.00 & 9.66 & 4.82 & 16.21 \\
\hline & St Dev & 00:03.6 & 87.39 & 84.94 & 62.93 & 9.22 & 1.40 & 0.71 & 3.17 \\
\hline & confidence & $00: 00.1$ & 3.05 & 2.96 & 2.19 & 0.32 & 0.05 & 0.02 & 0.11 \\
\hline
\end{tabular}



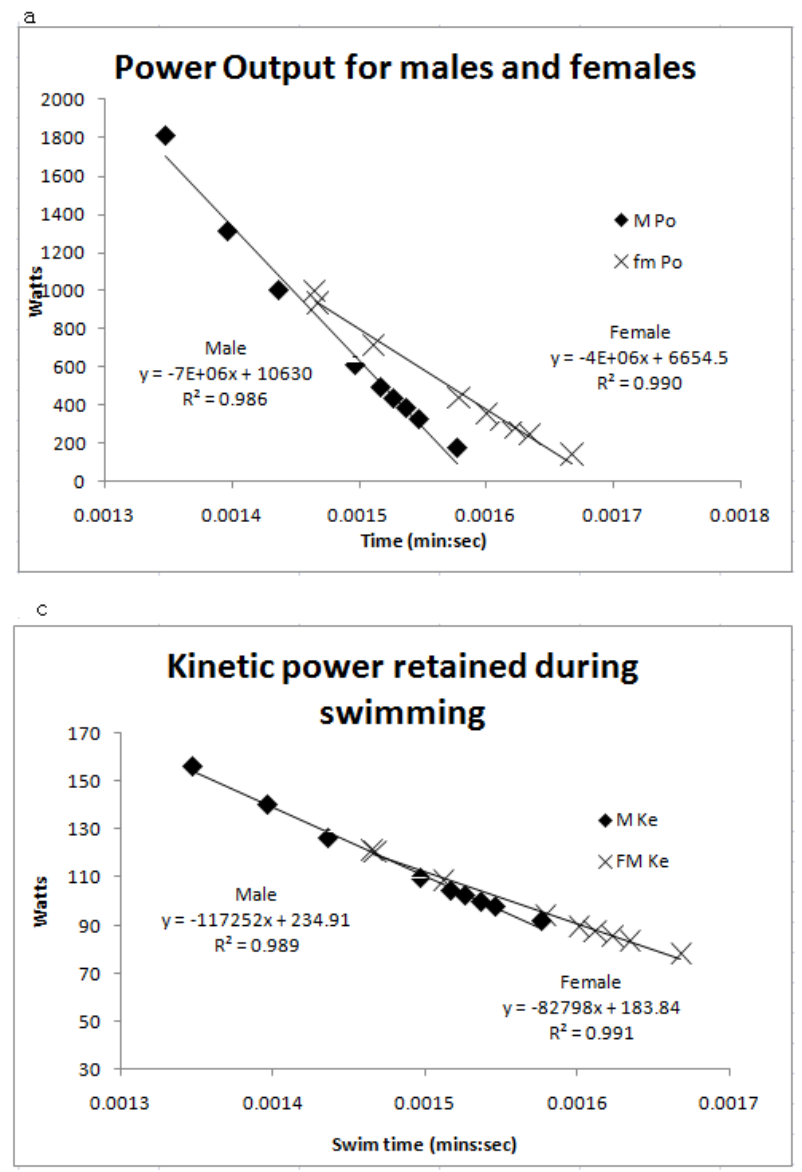
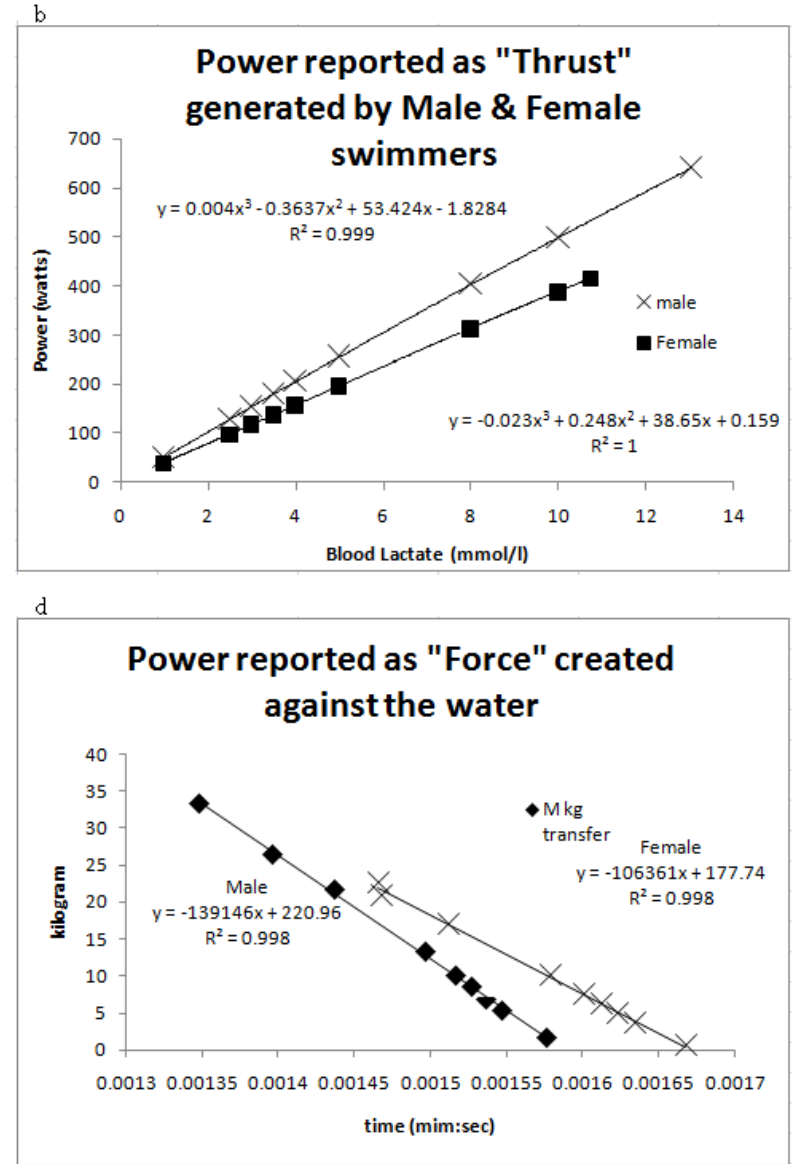

Figure 1. a,b,c,d.

Means and standard deviations for each criteria of power at each intensity are shown in these tables. Regression plots based upon the relationship of Power Input, Thrust, kinetic energy and force against the water are shown in Figure 1 abcd. These include regression equations and $\mathrm{r}^{2}$ values for males and females.

Because these figures are calculated for set intensities, we also used raw data to do multiple regression analysis that revealed that no particular indices was any better than the others for prediction of time for either males of females. The best predictor for women was thrust, kinetic energy and force created against the water were the best predictor of speed, $\mathrm{R}^{2}=.962$ time $\mathrm{sec}=188.84+0.2027$

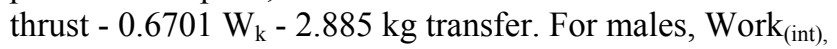
kinetic energy and force created against the water were the best predictor, the $\mathrm{R}^{2}=.967$; time $\mathrm{sec}=174.94+0.01549$ $\mathrm{W}_{\text {int }}$ watts $-0.5023 \mathrm{~kg}$ transfer $-0.4277 \mathrm{~W}_{\mathrm{k}}$.

\section{Discussion}

The purpose of this study was to determine power output in swimming during a commonly used step test. Power has been used to describe performance in cycling $[23,24]$, rowing [25] and kayakers [26]. Power in swimming has been difficult to measure and to define also. Indirect measurement [9] and direct measurement by the MAD system $[4,8]$ both produced differing output readings.

We wanted to derive the measurement of power in swimming in a way that that is easily applied, accurate and understandable for coaches. Additionally we needed to define meaning of the numbers produced so that they could be applied appropriately and increase understanding of the relationship of power to swimming speed. As with other sports (particularly cycling) the use of power has made it easier to more precisely describe performance, and where limitation occurs. Previous studies that have described power in swimming have shown power levels far below that seen in other sports for athletes of similar levels of performance $[4,8,9]$

The participants of the present study were all of a similar standard of performance achievement at an international level. They were all focused on 200 or $400 \mathrm{~m}$ events and were in a good state of fitness (ready to compete) that is seen by the test times swum. As such we would expect power output of swimmers to be in a similar range to athletes from other sports at key markers of intensity such as the individual anaerobic threshold, $\mathrm{MVO}_{2}$ or at maximal intensity.

Compared to rowers, where power is delivered by the upper body, similarly with swimming, our results for Work $_{(\text {tot })}$ at IAT $(384 \pm 28.99 \mathrm{w}$ vs $294 \pm 18.15 \mathrm{w})$ and those of Beneke (1995) [27], MLSS = $287 \pm 25.1$, Hagerman (1984) [25], elite rowers racing 7 mins $\mathrm{M}=\mathrm{M}$ $=390 \pm 13.6, \mathrm{FM}=300 \pm 18.4$ ), and Sharbolt (1999) [28], $313 \pm 38$ ), were closely aligned. Similar values reported by Mujika (2001) [29] for professional cyclists in the tour de France had LT values of 370 to $390 \mathrm{w}$ and OBLA between 400 and $420 \mathrm{~W}$. These compare favourably with our values for males swimmers. Where differences may occur is in muscle mass producing power is generated (upper body in swimming/lower body in cycling). 
Our figures for $\mathrm{MVO}_{2}$ were significantly higher for $\mathrm{W}_{\text {tot }}$ and $\mathrm{W}_{\text {int }}$ than those found by Billat et al [26] with cyclists. Where differences may occur in this is the definition of $\mathrm{MVO}_{2}$. In that study, cyclists rode for nearly 4 minutes, and were at the slowest speed that elicits MVO2, where our definition of $\mathrm{MVO}_{2}$ focuses on the highest speed that would elicit this effort, and a 2 minute time line similar to that used by Medbo et al [30]. The differences are big. This may be a function of the increased drag associated with the acceleration in water over that of air. As such it would suggest that at higher velocities it would be dangerous to not take account of drag as suggested earlier. Particularly at higher velocities, above the IAT for example, the determinant of power in swimming may have changed.

It has been reported that at lower speeds the contribution of arm stroke internal work to speed is low Zamparo et al [5], However this changes in sprint and maximal swims where power output should be maximized.

Compared to the previous swimming studies, the current methods showed similarities between measurements of $\mathrm{W}_{\mathrm{k}}$ to the figures of previous studies [4,8]. These studies demonstrated significantly lower figures for power than for other sports. It is likely that all athletes of a similar level of performance on similar time lines of exercise and effort, would be expected to generate similar levels of power. It is the method of delivery and medium in which it is delivered that would alter how we could define this power. Assuming that the $\mathrm{W}_{\text {tot }}$ is similar and that the $\mathrm{W}_{\text {int }}$ generated, ( $\mathrm{W}_{\text {tot }}$ minus $\mathrm{W}_{\mathrm{k}}$ ) is also similar, then $\mathrm{W}_{\mathrm{k}}$ (that which is retained in the body) would be more likely to be what has been measured in swimming. The values obtained by Toussaint were for $23 \mathrm{~m}$ swims and as such represent a much shorter effort than the $200 \mathrm{~m}$ swims used in this study. In this case, our measurements for $\mathrm{W}_{\mathrm{k}}$ were at maximum $(\mathrm{FM}=121.49 \pm 10.98 \mathrm{w}$, $\mathrm{M}=156.65 \pm 11.50 \mathrm{w})$ are interestingly similar to those described by previous studies.

Where the medium of measurement for swimmers changed, by use of a fixed bio-kinetic swim bench [9] the type of power measured is also likely to be different. In this instance, where the body is fixed and power generated was against resisted hand paddles. The power reported by Sharp et al [9] and those we reported for $\mathrm{W}_{\text {int }}$ were similar for males $(286.17 \pm 14.18 \mathrm{w}$ vs $283.77 \pm 20.3 \mathrm{w})$. Females in this study demonstrated lower $\mathrm{W}_{\text {int }}$ than the values reported by Sharp $(125 \pm 10.93 \mathrm{w}$ vs $164.50 \pm 11.90 \mathrm{w})$. This may make the figures found by use of a swim bench more understandable in terms of their application to swimming.

\section{Conclusion}

We defined methods by which to calculate power in swimming. These methods appear to produce robust figures that are comparable with values obtained in other sports. Due to the nature of how power is developed and delivered in different sports, the "Type" of power defined has to be considered. Previously "Power" measured in swimming has returned significantly lower values than would be expected for athletes of similar levels of performance in different sports (Cycling, Rowing, Speed
Skating, Kayakers). By defining the different types of power being measured, the values obtained by our swimmers at IAT compared favourably with both cyclists and rowers. The definition of thrust power and $\mathrm{W}_{\mathrm{k}}$ also allowed a better understanding of the type and amount of power previously measured for swimmers. The benefits of quantifying workload through power include improving training specific that can improve performance. we feel we have made a good explanation of what power swimmers actually develop and how to define that accordingly for sensible comparison.

\section{References}

[1] Jain, Mahesh C. Textbook of Engineering Physics (Part 1). PHI Learning Pvt. Ltd. P9. ISBN 81-203-3862-6, 2009.

[2] Schultz, William W., and Paul W. Webb. "Power requirements of swimming: Do new methods resolve old questions?." Integrative and Comparative Biology 42.5 (2002): 1018-1025.

[3] Koutedakis, Y., and N. C. Sharp. "A modified Wingate test for measuring anaerobic work of the upper body in junior rowers." British Journal of Sports Medicine 20.4 (1986): 153-156.

[4] Toussaint, Huub M., and Kees Vervoorn. "Effects of specific high resistance training in the water on competitive swimmers." International Journal of Sports Medicine 11, no. 03 (1990): 228-233.

[5] Zamparo, Paola, David R. Pendergast, Albert Termin, and Alberto E. Minetti. "Economy and efficiency of swimming at the surface with fins of different size and stiffness." European Journal of Applied Physiology 96, no. 4 (2006): 459-470.

[6] Toussaint, Huub, and Martin Truijens. "Biomechanical aspects of peak performance in human swimming." Animal Biology 55, no. 1 (2005): $17-40$.

[7] Toussaint, Huub M., and Peter J. Beek. "Biomechanics of competitive front crawl swimming." Sports medicine 13, no. 1 (1992): 8-24.

[8] Toussaint, Huub M., and Martin Truijens. "Power requirements for swimming a world-record 50-m front crawl." International journal of sports physiology and performance 1, no. 1 (2006): 6164.

[9] Sharp, Rick L., and John P. Troup. "Relationship between power and sprint freestyle." Medicine and Science in Sports and Exercise 14.1 (1982): 53-56.

[10] Hawley, John A., M. M. Williams, M. M. Vickovic, and P. J. Handcock. "Muscle power predicts freestyle swimming performance." British Journal of Sports Medicine 26, no. 3 (1992): 151-155.

[11] Toussaint, H. M., G. De Groot, H. H. C. M. Savelberg, K. Vervoorn, A. P. Hollander, and G. J. van Ingen Schenau. "Active drag related to velocity in male and female swimmers." Journal of Biomechanics 21, no. 5 (1988): 435-438.

[12] Hollander, A. P., G. De Groot, G. J. van Ingen Schenau, H. M. Toussaint, H. De Best, W. Peeters, A. Meulemans, and A. W. Schreurs. "Measurement of active drag during crawl arm stroke swimming." Journal of Sports Sciences 4, no. 1 (1986): 21-30.

[13] Capelli, Carlo, Dave R. Pendergast, and B. Termin. "Energetics of swimming at maximal speeds in humans." European journal of applied physiology and occupational physiology 78, no. 5 (1998): 385-393.

[14] Ogita, F., M. Hara, and I. Tabata. "Anaerobic capacity and maximal oxygen uptake during arm stroke, leg kicking and whole body swimming." Acta Physiologica 157, no. 4 (1996): 435-441.

[15] Di Prampero, P. E., C. Capelli, P. Pagliaro, G. Antonutto, M. Girardis, P. Zamparo, and R. G. Soule. "Energetics of best performances in middle-distance running." Journal of Applied Physiology 74, no. 5 (1993): 2318-2324

[16] Toussaint, Huub M., and A. Peter Hollander. "Energetics of competitive swimming." Sports Medicine 18, no. 6 (1994): 384-405.

[17] Wilmore, Jack H., and Albert R. Behnke. "An anthropometric estimation of body density and lean body weight in young men." Journal of Applied Physiology 27, no. 1 (1969): 25-31. 
[18] Margaria, R., P. Cerretelli, P. Aghemo, and G. Sassi. "Energy cost of running." Journal of applied physiology 18, no. 2 (1963): 367-370.

[19] Di Prampero, P. E. "The energy cost of human locomotion on land and in water." International journal of sports medicine 7, no. 02 (1986): 55-72.

[20] Vennell, Ross, Dave Pease, and Barry Wilson. "Wave drag on human swimmers." Journal of biomechanics 39, no. 4 (2006): 664-671.

[21] Takagi, Hideki, Yukimaru Shimizu, Hiroshi Onogi, and Yoshitane Kusagawa. "The relationship between coefficients of drag and swimming performance." In 2nd Australia and New Zealand Society of Biomechanics Conference, Auckland, New Zealand. 1998.

[22] Gore, C. J. "Physiological test for elite athletes. Australian sports commission." Champaign, Il.: Human Kinetics, 2000. 465 h(2000).

[23] Coyle, E. F., M. E. Feltner, S. A. Kautz, M. T. Hamilton, S. J. Montain, A. M. Baylor, L. D. Abraham, and G. W. Petrek. "Physiological and biomechanical factors associated with elite endurance cycling performance." Medicine and science in sports and exercise 23, no. 1 (1991): 93-107.

[24] Vogt, Stefan, Lothar Heinrich, Yorck Olaf Schumacher, Andreas Blum, Kai Roecker, Hans-hermann Dickhuth, and Andreas Schmid. "Power output during stage racing in professional road cycling." Medicine \& Science in Sports \& Exercise 38, no. 1 (2006): 147-151.

[25] Hagerman, Fredrick C. "Applied physiology of rowing." Sports Medicine 1.4 (1984): 303-326.

[26] Billat, V., et al. "A comparison of time to exhaustion at [vdot] O2; max in elite cyclists, kayak paddlers, swimmers and runners." Ergonomics 39.2 (1996): 267-277.

[27] Beneke, Ralph. "Anaerobic threshold, individual anaerobic threshold, and maximal lactate steady state in rowing." Medicine and science in sports and exercise 27.6 (1995): 863-867.
[28] Schabort, E. J., J. A. Hawley, W. G. Hopkins, and H. Blum. "High reliability of performance of well-trained rowers on a rowing ergometer." Journal of Sports Sciences 17, no. 8 (1999): 627-632.

[29] Mujika, Iñigo, and Sabino Padilla. "Physiological and performance characteristics of male professional road cyclists." Sports Medicine 31, no. 7 (2001): 479-487.

[30] Medbo JI, Mohn AC, Tabata I, Bahr R, Vaage O, Sejersted OM. Anaerobic capacity determined by maximal accumulated $\mathrm{O} 2$ deficit. Journal of applied physiology. 1988 Jan 1; 64(1):50-60.

[31] Bassett Jr, David R., Chester R. Kyle, Louis Passfield, Jeffrey P. Broker, and Edmund R. Burke. "Comparing cycling world hour records, 1967-1996: modeling with empirical data." Medicine and Science in Sports and Exercise 31, no. 11 (1999): 1665-1676.

[32] Cordain, L., \& Kopriva, R. (1991). Wetsuits, body density and swimming performance. British Journal of Sports Medicine, 25(1), 31-33.

[33] Denadai, B. S., T. R. Figueira, O. R. P. Favaro, and M. Gonçalves. "Effect of the aerobic capacity on the validity of the anaerobic threshold for determination of the maximal lactate steady state in cycling." Brazilian Journal of Medical and Biological Research 37 no. 10 (2004): 1551-1556.

[34] Souza, Kristopher Mendes de, Talita Grossl, Babel Junior, Rubens José, Ricardo Dantas de Lucas, Vitor Pereira Costa, and Luiz Guilherme Antonacci Guglielmo. "Maximal lactate steady state estimated by different methods of anaerobic threshold." Revista Brasileira de Cineantropometria \& Desempenho Humano 14, no. 3 (2012): 264-275.

[35] van Schenau, Gerrit Jan Ingen, Jos J. de Koning, and Gert de Groot. "Optimisation of sprinting performance in running, cycling and speed skating." Sports Medicine 17, no. 4 (1994): 259-275.

[36] Toussaint, HUUB M., Wilma Knops, Gert De Groot, and A. Peter Hollander. "The mechanical efficiency of front crawl swimming." Medicine and Science in Sports and Exercise 22, no. 3 (1990): 402-408. 